BoTH anaesthetics and surgical trauma could strongly affect the production of tumour necrosis factor $\alpha$ (TNF $\alpha$ ). During in vitro experiments the authors found that anaesthetics modulate the production of TNF $\alpha$ by peripheral blood mononuclear cells. Notably, Pentothal strongly increased the production of the cytokine as compared to both lipopolysacchride treated and control mononuclear cells, whereas in supernatants from Leptofen driven mononuclear cells TNF $\alpha$ was strongly reduced. On the other hand, Pavulon did not significantly affect the cytokine production. In the in vivo study, in an attempt to ameliorate the metabolic response to surgical trauma, L-carnitine was administered to 20 surgical patients, then the circulating TNF $\alpha$ was measured. The results indicate that the levels of circulating TNF $\alpha$ were strongly increased following surgery and that L-carnitine administration resulted in a strong reduction of TNF $\alpha$. Thus, the data suggest that L-carnitine could be helpful in protecting surgical patients against dysmetabolism dependent on dysregulated production of TNF $\alpha$.

\section{Anaesthetics modulate tumour necrosis factor $\alpha$ : effects of L-carnitine supplementation in surgical patients. Preliminary results.}

\author{
Giovanna Delogu, ${ }^{1}$ Claudio De Simone, ${ }^{2, C A}$ \\ Giuseppe Famularo, ${ }^{3}$ Alessandra Fegiz, \\ Francesca Paoletti ${ }^{4}$ and Emilio Jirillo
}

\begin{abstract}
${ }^{1}$ Anaesthesiology and Intensive Care and "Infectious Diseases, University "La Sapienzie" Rome; ${ }^{2}$ Infectious Diseases and ${ }^{3}$ Internal Medicine, University of L'Aquila; ${ }^{5}$ Immunology,

University of Bari, Italy.
\end{abstract}

Key words: Anaesthetics, L-Carnitine, Surgery, TNF $\alpha$
${ }^{\mathrm{CA}}$ Corresponding Author

\section{Introduction}

Patients undergoing surgery may subsequently have life-threatening multiple organ failure (MOF). ${ }^{1}$ The dysregulated release of cytokines by macrophages is likely to play a major role in the pathogenesis of this disorder. ${ }^{2}$ Among macrophage derived cytokines, TNF $\alpha$ is pivotal since it is directly involved in mediating the organism adaptative response to injury, including surgery. ${ }^{3,4}$

Several anaesthetic agents are able to affect the pattern of cytokine production by monocytes/ macrophages in vitro, including $\mathrm{TNF} \alpha$, and several reports have confirmed that the confirmed administration of anaesthetics, profoundly derange the normal functions of the immune system in vivo. ${ }^{5-9}$

Here, the results of experiments are reported, which indicate that anaesthetic drugs, most notably Pentothal, could strongly enhance under in vitro conditions the TNF $\alpha$ production by peripheral blood mononuclear cells (PBMCs) from healthy individuals as compared to both lipopolysaccharide (LPS) treated and control cells. In addition, in in vivo studies the authors found that serum levels of $\mathrm{TNF} \alpha$ are significantly increased following surgery. The administration of L-carnitine resulted in the reduction of circulating TNF $\alpha$.

\footnotetext{
(C) 1993 Rapid Communications of Oxford Ltd
}

\section{Materials and Methods}

In vitro experiments:

PBMCs. PBMCs were obtained from healthy volunteers by standard methods, as described previously. ${ }^{10}$

Cell cultures. Briefly, PBMCs were resuspended at the concentration of $2 \times 10^{6}$ cells $/ \mathrm{ml}$ in $\mathrm{RPMI}$ 1640 (Gibco Bio Cult., Paisley, UK) containing 10\% heat-inactivated foetal calf serum, $1 \% \mathrm{~L}$-glutamine, and penicillin/streptomycin. PBMCs were cultured for $72 \mathrm{~h}$ in a $5 \% \mathrm{CO}_{2}$ atmosphere at $37^{\circ} \mathrm{C}$ in the presence of either standard LPS concentration, as described previously ${ }^{10}$ or anaesthetic drugs (Leptofen, Pavulon, Pentothal) at the optimal concentration of $10 \mu \mathrm{g} / \mathrm{ml}$. At the end of the culture period, the supernatants were harvested and TNF $\alpha$ was measured.

Measurement of $T N F \alpha$. TNF $\alpha$ was quantified by a sandwich enzyme immunoassay (Biokine, $\mathrm{T}$ Cell Sciences Inc., MA, USA), according to standard methods. ${ }^{11}$ The lower limit of TNF $\alpha$ detection in this immunoassay was $10 \mathrm{pg} / \mathrm{ml}$. Serum $\mathrm{TNF} \alpha$ measured in healthy volunteers was below this limit.

In vivo studies:

Patients. Twenty patients were admitted for surgery and randomly assigned to receive either 
NLA anaesthesia alone (Group 1) or NLA anaesthesia plus L-carnitine (Carnitene $^{\mathrm{TM}}, 1 \mathrm{~g}$ ampoules, Sigma Tau, Pomezia, Italy) (Group 2).

No patient was suffering from cancer or infections or had received any medical treatment before the admission to the study. Surgery was always performed by the same surgeon.

The patients were well matched with respect to age $(45 \pm 13$ and $47 \pm 9$ years), weight ( $71 \pm 2$ and $72 \pm 8 \mathrm{~kg}$ ), and height (166 \pm 24 and $170 \pm 26 \mathrm{~cm}$ ), in Group 1 and Group 2, respectively. Surgery was performed because of nephrolithiasis (one and two patients), uterocele (one and zero), hysteromyoma (one and one), colonic diverticula (four and five), megacolon (two and two), and irritable bowel syndrome (one and zero) in Group 1 and Group 2, respectively. The type of surgery was colonic resection in three and two, nephrectomy in one and two, hysterectomy in two and one, and hemicolectomy in four and five patients, in Group 1 and Group 2, respectively. Notably, the duration of surgery was comparable in both groups $(123 \pm 61$ and $139 \pm 52 \mathrm{~min}$ in Group 1 and Group 2, respectively) and the post-surgery course was not burdened by complications.

Informed consent was obtained from all subjects and the study was approved by the Hospital Ethics Committee on Human Research.

Anaesthetic technique. Premedication was performed with atropine sulphate $(0.5 \mathrm{mg}$ i.m.) and diazepam (10 mg i.m.) administered $40-50 \mathrm{~min}$ before the scheduled time of surgery. Then, anaesthesia was induced with droperidol $(2.5 \mathrm{mg})$, fentanyl $(0.1 \mathrm{mg})$ and thiopentone $(3.5 \mathrm{mg} / \mathrm{kg})$. Tracheal intubation was performed after administering pancuronium $(0.08 \mathrm{mg} / \mathrm{kg}$ ). Anaesthesia was maintained with $60 \%$ nitrous oxide in oxygen. Supplementary doses of fentanyl, droperidol, and pancuronium were given as needed. Mean doses were fentanyl, $0.056 \pm$ $0.02 \mathrm{mg}$; pancuronium, $8.3 \pm 0.6 \mathrm{mg}$; droperidol, $3.8 \pm 0.5 \mathrm{mg}$. At the end of surgery, residual neuromuscular blockade was antagonized with a mixture of atropine and neostigmine. All anaesthetic drugs were administered by the same anaesthetist.

Post-surgery care. All patients in both groups were given buprenorphine $0.3 \mathrm{mg}$ for analgesia on the day of surgery only.

L-carnitine treatment. In Group 2 patients, L-carnitine was administered i.v. at the dosage of $8 \mathrm{~g}$ at the end of surgery and $24 \mathrm{~h}$ afterwards.

Blood sampling. Samples of peripheral blood were obtained for TNF $\alpha$ measurement on the day before surgery and 2,24 , and $48 \mathrm{~h}$ after surgery $(\mathrm{t} 0, \mathrm{t} 1, \mathrm{t} 2$, $\mathrm{t} 3$, respectively).
Samples of peripheral blood were obtained for carnitine measurement at $\mathrm{t} 0, \mathrm{t} 2$, and $\mathrm{t} 3$, respectively. Since the time lag between the end of surgery (L-carnitine administration) and blood drawing $(2 \mathrm{~h})$ was too short, no samples were collected at $\mathrm{t} 1$. In Group 2 patients, samples of peripheral blood were obtained before L-carnitine administration.

L-carnitine measurement. Serum levels of carnitines were measured by using standard methods, as described previously. ${ }^{12}$ Briefly, a neutralized perchloric acid extract of plasma was incubated with ${ }^{14} \mathrm{C}$-acetyl coenzyme $\mathrm{A}(\mathrm{CoA})$ in the presence of carnitine acetyltransferase (CAT). Then, the labelled acetyl L-carnitine was separated from the unreacted ${ }^{14} \mathrm{C}$-acetyl $\mathrm{CoA}$ by an anion exchange resin and radioactivity counts were measured in the supernatant. This method allows the quantitative evaluation of L-carnitine (free carnitine) and L-carnitine formed from alkaline hydrolysis as an expression of the total acid soluble L-carnitine. Short-chain L-carnitine esters were measured as the difference between total acid soluble L-carnitine and free L-carnitine.

Statistical analysis: Results are expressed as the mean \pm standard deviation. The differences between groups for paired and unpaired data were statistically significant for $p$ less than 0.01 .

\section{Results}

In vitro experiments: The LPS stimulation of PBMCs proved to strongly increase the $T N F \alpha$ release in culture media as compared to unstimulated PBMCs $(p<0.05)$, as expected (Fig. 1). However, Pentothal was significantly more effective with respect to LPS in inducing TNF $\alpha$ synthesis and release by PBMCs $(p<0.001)$ (Fig. 1). The stimulation of PBMCs with other anaesthetic drugs, such as Pavulon and Leptofen, did not result in increased TNF $\alpha$ production. In supernatants from Leptofen driven PBMC cultures TNF $\alpha$ levels were strongly reduced compared to both LPS driven and unstimulated cultures $(p<0.05)$, whereas in supernatants from Pavulon driven PBMC cultures TNF $\alpha$ was similar to that in unstimulated cultures (Fig. 1).

In preliminary experiments, the addition of L-carnitine at various doses to anaesthetic driven PBMC cultures was followed by conflicting effects on the pattern of TNF $\alpha$ production (data not shown). Further studies to establish both the optimal dosage and kinetics of adding L-carnitine to PBMC cultures in order to obtain a clear-cut modulation of anaesthetic driven TNF $\alpha$ production are therefore needed.

In vivo studies: Patients in Groups 1 and 2 were well matched for age, weight, height, types and/or 


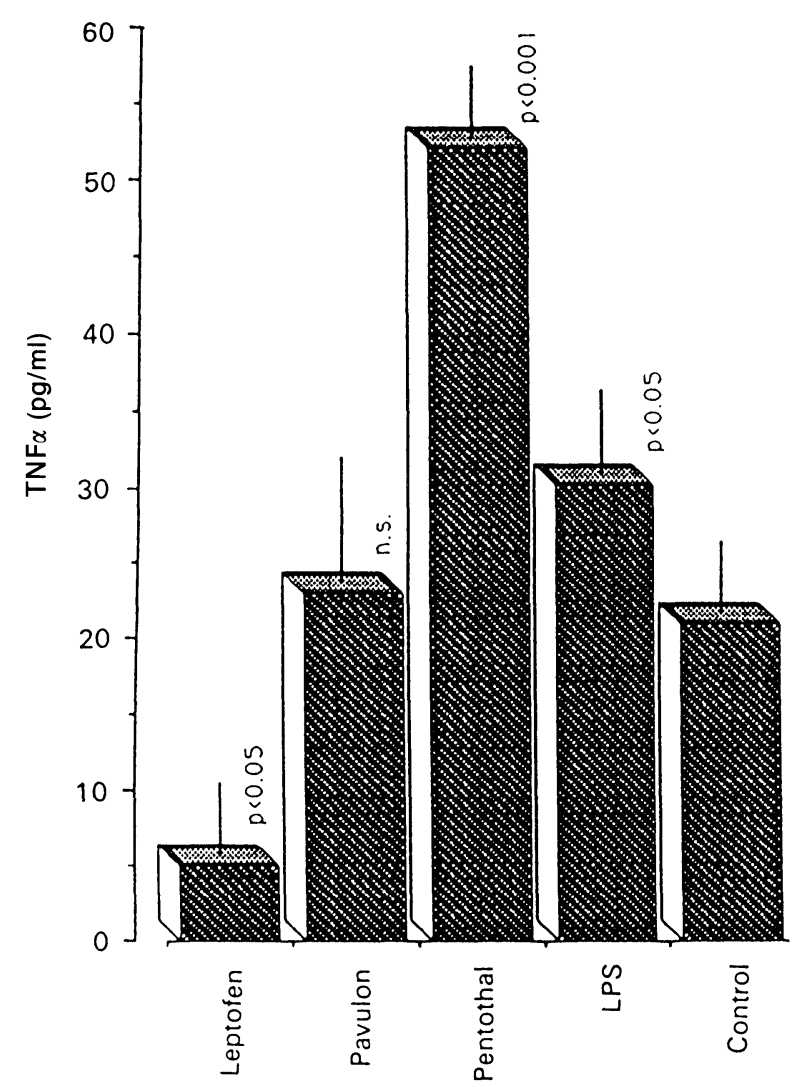

FIG. 1. TNF $\alpha$ levels in supernatants of PBMCs driven by eithe anaesthetics (Leptofen, Pavulon, Pentothal) or LPS as well as in supernatants of unstimulated PBMCs. Anaesthetics were used at the optimal concentration of $10 \mu \mathrm{g} / \mathrm{ml}$. The results are shown as the mean levels of TNF $\alpha$ of triplicate experiments \pm standard deviation. See Materials and Methods for details.

duration of surgery. During surgery, blood loss ranged from 600 to $1200 \mathrm{ml}$. Nevertheless, patients did not require blood transfusion and received conventional crystalloid or colloid (Dextran 70) fluids. Both Group 1 and Group 2 patients did not exhibit any complication throughout their course and the body temperature following surgery did not exceed $38.2^{\circ} \mathrm{C}$. The pattern was similar in both groups. Finally, any treatment related adverse effect was recorded in patients receiving L-carnitine.

The effects of surgical/anaesthetic trauma on $\mathrm{TNF} \alpha$ serum levels are shown in Table 1. At t0, all

Table 1. Serum levels of $T N F \alpha(p g / m l)$ following surgical/ anaesthetic trauma in patients receiving placebo (Group 1 ) and L-carnitine (Group 2)

\begin{tabular}{lcc}
\hline Time & \multicolumn{2}{c}{ Patients } \\
\cline { 2 - 3 } & Group 1 & Group 2 \\
\hline t0 & $5 \pm 2$ & $6 \pm 2$ \\
t1 & $40 \pm 2^{*}$ & $30 \pm 5^{*}$ \\
t2 & $68 \pm 8^{* * a}$ & $15 \pm 4$ \\
t3 & $62 \pm 7^{* * \mathrm{~b}}$ & $22 \pm 9$ \\
\hline
\end{tabular}

${ }^{*} p<0.01$ with respect to to; ${ }^{* *} p<0.001$ with respect to t0; ${ }^{a} p<0.001$ with respect to Group $2 ;{ }^{b} p<0.01$ with respect to group 2. For t0, t1, t2, and $\mathrm{t} 3$ see Materials and Methods. patients had circulating TNF $\alpha$ within the normal range. In Group 1, a significant increase of plasma levels of TNF $\alpha$ was found throughout $t 1$ $(40 \pm 2 \mathrm{pg} / \mathrm{ml} ; p<0.01)$ to $\mathrm{t} 3 \quad(62 \pm 7 \mathrm{pg} / \mathrm{ml}$; $p<0.001)$, peaking at $\mathrm{t} 2(68 \pm 8 \mathrm{pg} / \mathrm{ml} ; p<0.001)$, with respect to serum levels at to $(5 \pm 2 \mathrm{pg} / \mathrm{ml})$. In Group 2 patients strongly increased $(p<0.01)$ serum levels of TNF $\alpha$ were found only at t1 $(30.3 \pm 5 \mathrm{pg} / \mathrm{ml})$ compared to t0 $(6 \mp 2 \mathrm{pg} / \mathrm{ml})$; at $\mathrm{t} 2 \quad(15 \pm 4 \mathrm{pg} / \mathrm{ml})$ and $\mathrm{t} 3 \quad(22 \pm 9 \mathrm{pg} / \mathrm{ml})$ $\mathrm{TNF} \alpha$ was not significantly different with respect to t0. Notably, serum levels of TNF $\alpha$ were significantly different between Group 1 and Group 2 patients only at $\mathrm{t} 2(p<0.001)$ and $\mathrm{t} 3(p<0.01)$.

Total, free, and short-chain carnitine levels were comparable in the two groups and within the normal range at t0 (Table 2). In Group 1 patients, no significant change of total, free, and short-chain carnitine was found at $\mathrm{t} 2$ and $\mathrm{t} 3$ (Table 2). However, in Group 2 patients serum carnitine levels were increased significantly at $\mathrm{t} 2$ and $\mathrm{t} 3$ with respect to baseline values, as expected (Table 2).

\section{Discussion}

The results indicate that anaesthetic drugs can affect TNF $\alpha$ production and release by monocytes/macrophages, under in vitro conditions. However, strong differences exist among anaesthetic drugs in their ability to modulate $\mathrm{TNF} \alpha$ production, as suggested by the finding that Pentothal strongly enhanced the cytokine production compared to LPS, whereas both Pavulon and Leptofen did not. The demonstration that Pentothal is effective in inducing TNF $\alpha$ is consistent with the hypothesis that surgical patients treated with Pentothal could be at risk of MOF, since TNF $\alpha$ is

Table 2. Total, free, and short-chain carnitine $(\mathrm{nmol} / \mathrm{ml})$ in serum from patients receiving placebo (Group 1) and L-carnitine (Group 2)

\begin{tabular}{ccc}
\hline \multirow{2}{*}{ Time } & \multicolumn{2}{c}{ Patients } \\
\cline { 2 - 3 } & Group 1 & Group 2 \\
\hline Total carnitine & & \\
t0 & $30 \pm 7$ & $34 \pm 8$ \\
t2 & $50 \pm 9$ & $312 \pm 71^{*}$ \\
t3 & $39 \pm 4$ & $566 \pm 215^{*}$ \\
Free carnitine & $34 \pm 7$ & \\
t0 & $39 \pm 6$ & $28 \pm 8$ \\
t2 & $28 \pm 8$ & $518 \pm 245^{*}$ \\
t3 & & \\
Short-chain carnitine & $6.5 \pm 3.5$ & $9.7 \pm 4.8$ \\
t0 & $5.1 \pm 1.9$ & $19 \pm 6^{*}$ \\
t2 & $4.5 \pm 2.7$ & $34 \pm 5^{*}$ \\
t3 & &
\end{tabular}

${ }^{*} p<0.001$ with respect to both t0 and Group 1 . For $t 0, t 2$, and t3. See Materials and Methods. 
directly involved in the pathogenesis of the disorder. However, anaesthetic drugs per se could also down-modulate the production of TNF $\alpha$, as shown by Leptofen, or not exhibit any effect at all, as is the case of Pavulon. Therefore, the pathophysiological pathways leading to the increased serum levels of TNF $\alpha$ following surgery, which were demonstrated in the in vivo study, may not be strictly dependent on the immunomodulating properties of the anaesthetic drugs per se. Further studies are needed to fully understand the complex network of immune and endocrine events which account for the increased TNF $\alpha$ production following surgical injury. In fact, the recently reported ability of benzodiazepines to modulate IL-1, IL-6, and TNF $\alpha$ synthesis by human monocytes/macrophages ${ }^{13}$ further emphasizes the complexity of the pathophysiological phenomena occurring throughout anaesthesia and surgery.

In the patients enrolled in this trial, serum carnitine levels did not substantially change following surgery, whereas increased levels were found in patients receiving L-carnitine, as expected. In these latter patients, serum TNF $\alpha$ was strongly reduced at $\mathrm{t} 2$ and $\mathrm{t} 3$ compared to placebo treated subjects. These preliminary data clearly suggest that the treatment with L-carnitine could protect surgical patients against the dysregulated production of monocyte/macrophage derived cyto- kines, most notably TNF $\alpha$, which can lead to MOF and death.

\section{References}

1. Weissman $\mathrm{C}$. The metabolic response to stress: an overview and update. Anaesthesiology 1990; 73: 298-327.

2. Salo M. Effects of anaesthesia and surgery on the immune response. Acta Anaesthesiol Scand 1992; 36: 201-220.

3. Spooner CE. The role of tumour necrosis factor in sepsis. Clin Immunol Immunopatbol 1992; 62: S11-S17.

4. Tracey KJ. The acute effects of chronic pathophysiologic effects of TNF mediation of septic shock and wasting (cachexia). In: Beutler B, ed. Tumour necrosis factors. The molecules and their emerging role in medicine. New York: Raven Press, 1992; 255-273.

5. Rossano F, Tufano R, Cipollone G, et al. Anaesthetic agents induce circulating mononuclear leukocytes to release cytokines. Immunopharmacol Immunotoxicol 1992; 14: 439-450.

6. Mondgill GC. Update on anaesthesia and the immune response. Can Anaesth Soc J 1986; 33: S54-S71.

7. Stevenson GW, Hall S, Rudnick SJ, et al. Halothane anaesthesia decreases human monocyte hydrogen peroxide generation. Protection of monocyte by activation with gamma-interferon. Immunopharmacol Immunotoxicol 1987; 9 : 489-494.

8. Tonnesen E, Srinkla MM, Christensen NJ, Olsen AS, Hadsen J. Natural killer activity and lymphocyte function during and after coronary artery by-pass grafting to the endocrine stress response. Anaesthesiology 1987; 67 526-530.

9. Pertilla S, Salo M, Rajanaki A. Granulocyte microbicidal function in patients undergoing major abdominal surgery under balanced anaesthesia. Acto Anaesthesiol Scand 1987; 31: 100-103.

10. Famularo G, Giacomelli R, Di Giovanni S, Sacchetti S, Tonietti G. Cytokine production in patients with monoclonal gammopathies. J Clin Lab Immunol 1991; 34: 63-70.

11. De Simone C, Tzantzoglou S, Famularo G, et al. High-dose L-carnitine improves immunologic and metabolic parameters in AIDS patients. Immunopharmacol Immunotoxicol 1993; (in press).

12. De Simone C, Tzantzoglou S, Jirillo E, Marzo A, Vullo V, Arrigoni Martell E. L-carnitine deficiency in AIDS patients. AIDS 1992; 6: 203-205.

13. Taupin V, Jayais P, Descamps-Latscha B, et al. Benzodiazepine anaesthesia in humans modulates the interleukin- $1 \beta$, tumour necrosis factor alpha, and interleukin-6 responses of blood monocytes. J Neuroimmunol 1991; 35: 13-19. 




The Scientific World Journal
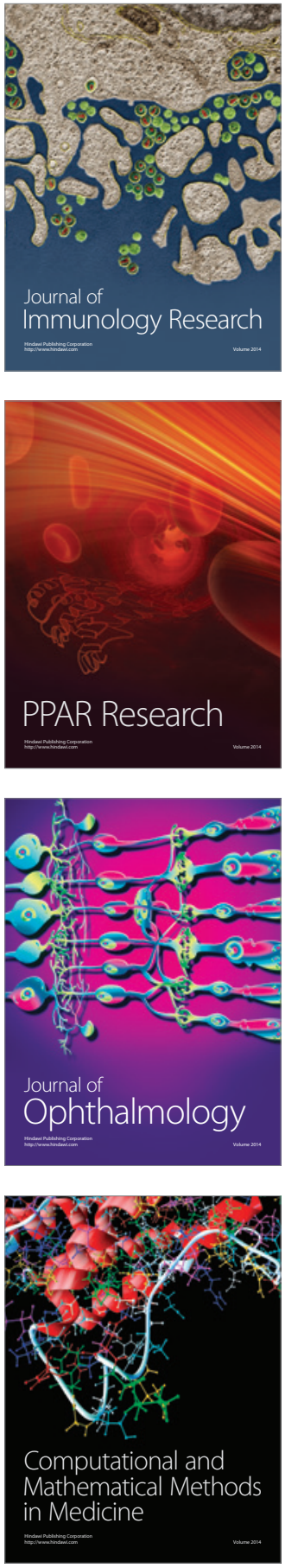

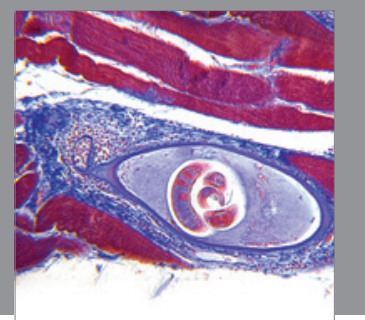

Gastroenterology

Research and Practice
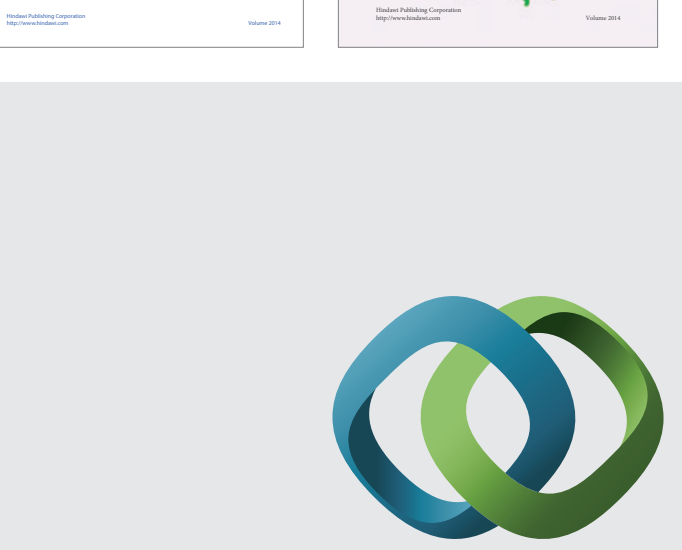

\section{Hindawi}

Submit your manuscripts at

http://www.hindawi.com
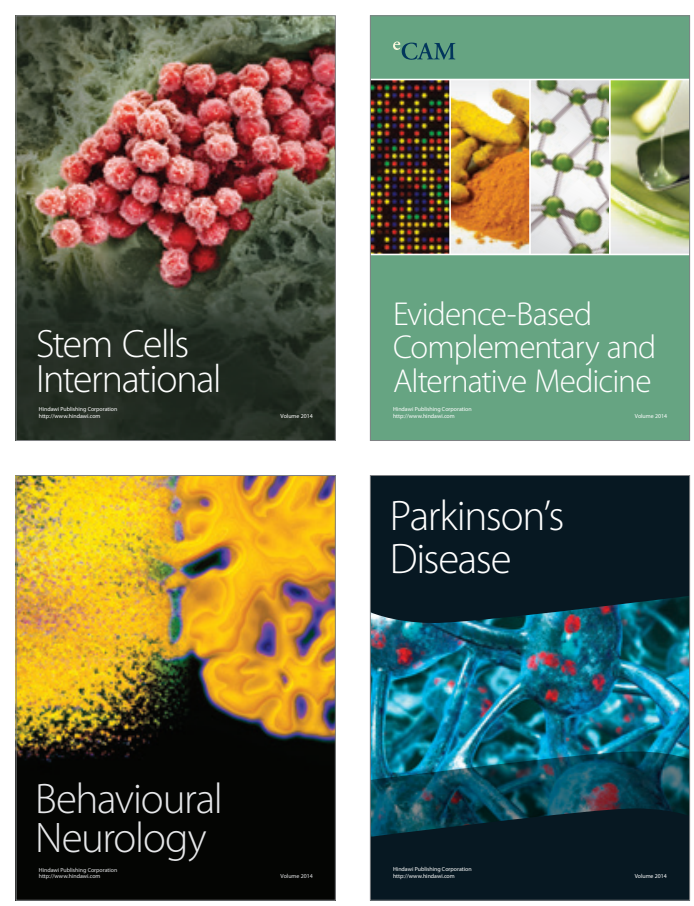

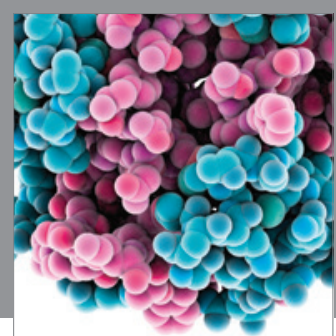

Journal of
Diabetes Research

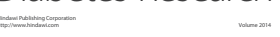

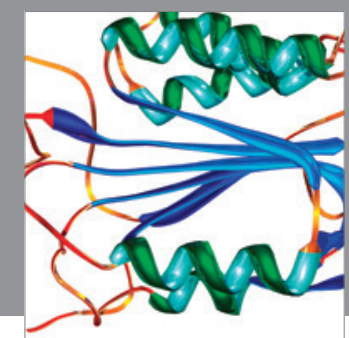

Disease Markers
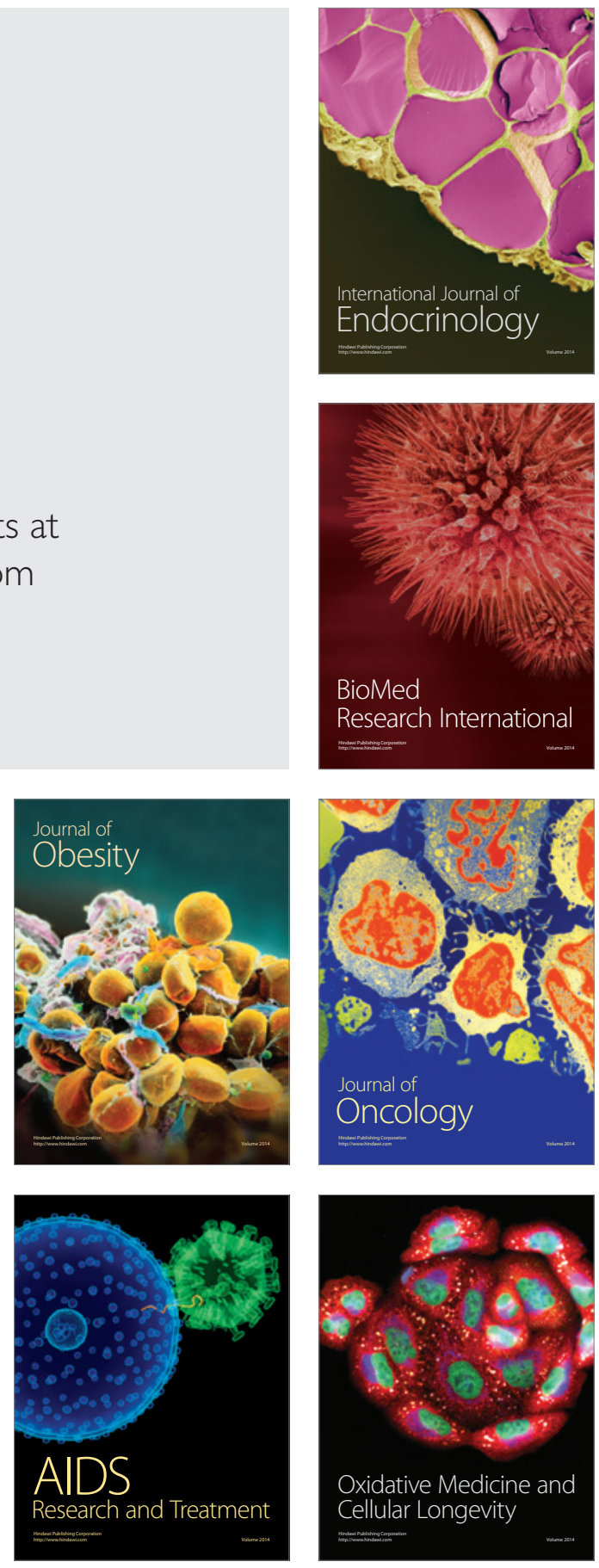